\title{
Physicians and Conflicts of Interest
}

\author{
Deborah Pimentel1,2*, Maria-Jésia Vieira ${ }^{3}$, João Pedro Declerc F. S. Neves², \\ Manoel Juvenal da Costa-Neto ${ }^{4}$, Laís Costa Souza Oliveira ${ }^{3}$ \\ ${ }^{1}$ Department of Medicine, Universidade Federal de Sergipe, Aracaju, Brazil \\ ${ }^{2}$ Universidade Tiradentes, Aracaju, Brazil \\ ${ }^{3}$ Postgraduate Program in Health Sciences, Universidade Federal de Sergipe, Aracaju, Brazil \\ ${ }^{4}$ Universidade Federal de Sergipe, Aracaju, Brazil \\ Email: ${ }^{*}$ deborah@infonet.com.br
}

Received 11 June 2014; revised 10 July 2014; accepted 9 August 2014

Copyright (C) 2014 by authors and Scientific Research Publishing Inc.

This work is licensed under the Creative Commons Attribution International License (CC BY). http://creativecommons.org/licenses/by/4.0/

\section{c) (i) Open Access}

\section{Abstract}

In medical practice, the most commonly observed conflicts of interest are the ones existing in the relations between professionals and industries linked to health or between the former and health services. These relations are no longer a partnership in search of the best to be offered to patients and tend to take up a commercial role, in a seduction game where, each one, in their own manner, seeks benefits. The purpose of this study is to analyze the existence of these conflicts of interest, in an exploratory and qualitative study, with physician focal groups. The results were grouped in two categories: benefits received by physicians and the justifications provided by them for the establishment of these partnerships. The most common benefits are: percentages over orthoses and prosthetics received by the industry; discounts and credits on rent or condominium fees for exam indications and procedures; rewards offered by the pharmaceutical industry for the indication of their products. Physicians have pointed out as main determinants for ethical missteps that involve conflicts of interest, the character and family formation as well as the lack of denunciations. The fact that efficient and widespread laws for resolution of conflicts of interest do not exist makes it necessary to recognize their existence with mechanisms of management and transparency, perhaps as the only way to avoid negative interference in physician behavior.

\section{Keywords}

Ethics, Physicians, Conflicts of Interest

\section{Introduction}

When divergences among health professionals' and institutions' attitudes are noted, and/or their responsibilities

\footnotetext{
${ }^{*}$ Corresponding author.
}

How to cite this paper: Pimentel, D., Vieira, M.-J., Neves, J.P.D.F.S., da Costa-Neto, M.J. and Oliveira, L.C.S. (2014) Physicians and Conflicts of Interest. International Journal of Clinical Medicine, 5, 956-965. 
to the patients and society, one may observe conflicts of interest. They generally involve concerning practices that may compromise the trust of patients in relation to professionals, especially physicians and health centers [1] [2].

One may say that there are conflicts of interest when the apparent motives, such as altruism, are not actually the force that moves people in decision making and hide other less noble reasons, such as profit. Conflicts become increasingly present whenever there is a personal benefit on an issue that may introduce a bias, directly affecting a decision or a result [3].

The pharmaceutical industry and equipment are among the causes of conflict, setting the new rules, transforming the medical profession into a commercial activity. Therefore, several decades ago, relations between physicians and industry, particularly the pharmaceutical one, have been the target of much criticism, by physicians and other health professionals, the industry itself, by the class counsel, the specialty societies, by media in general and patients [4] [5].

Many people blame the industry solely for such abuses, but doctors have a key role in this context, because without them, these industries would have no power. They are doctors who have the pen as a powerful tool to prescribe and indicate whatever they find fit as how to treat their patients, according to the benefits, which are convenient for them [1].

It appears that, in the midst of ethical conflicts, there is the patient with his/her therapeutic demands on one hand and the physician with his/her unjustifiable material needs on the other hand, not prescribing his/her patient in a personalized way, but contemplating a production that justifies the awards, gifts and trips received from the industry.

This study aims to analyze the presence of conflicts of interest between physicians and industries that maintain ties to the health area and thereby contribute to further reflection where there is on the ethical issues surrounding these relations, sometimes harmful and with implications for patients.

\section{Methodology}

This paper provides an outline of the general results of the doctoral thesis "The ethics of relations: an approach to academic training and professional practice”, whose project was approved by the Ethics in Human Research Committee of the Federal University of Sergipe in June, 01, 2007 under number CAAE 0046.0.107.000-07.

This is a qualitative study of exploratory nature held with health professionals and among them 141 doctors in Aracaju/SE. This professional category, after answering a mixed instrument that aimed to determine the contribution of ethics in their degree course to face current conflicts, agreed to participate in in-depth interviews to discuss the major ethical conflicts experienced in their practice.

Three focus groups were conducted [6]-[8] during two months, with an average of seven participants (21 doctors) who pre-authorized recording and transcript of her speech, through a Term of Consent, which ensured personal and institutional confidentiality and anonymity.

The meetings were held in the Regional Council of Medicine and lasted an average of two hours. Each meeting had two moderators and two observers recorded the nonverbal reactions and attitudes of participants that might have some value in the interpretations and discussions after the verbal contents have been subjected to a categorical analysis to extract sense nuclei [9].

\section{Results}

The medical members of the focus groups lived in Aracaju/Sergipe/Brazil and 59\% of them were male. The vast majority, $72 \%$, had graduated from a public university in the state of Sergipe, with a time of clinical experience predominantly in two bands, namely: 25\% between 6 and 10 years and $24 \%$ between 21 and 25 years.

The focus group participants performed their duties in a public hospital (41.7\%), in private hospitals (10.6\%), in public outpatient clinics (20.4\%), in private clinics (2.3\%) and 25\% of them work in more than one health institution.

Through an analysis of the material, the information extracted from the focal groups were condensed in sense nuclei, counted in register units and organized, in a comprehensive manner, into two categories: physicians that receive benefits, especially orthopedists, only specialty cited directly; and the formation of conflicts of interest (Table 1). 
Table 1. Conflicts of interest between physicians and clinics and hospitals and between physicians and health care related industries. Aracaju 2013.

\begin{tabular}{|c|c|c|}
\hline Categories & Sense nuclei & $\begin{array}{l}\text { Number of citations or } \\
\text { register units }\end{array}$ \\
\hline \multirow{5}{*}{$\begin{array}{l}\text { Physicians } \\
\text { receiving benefits }\end{array}$} & By indicating manipulation drugs laboratories & 05 \\
\hline & From drug companies & 10 \\
\hline & When reaching a minimum number of exams requested & 21 \\
\hline & During pharmaceutical company representatives visits & 06 \\
\hline & Percentage on the cost value of the orthopedic material used in patients & 22 \\
\hline \multirow{6}{*}{$\begin{array}{l}\text { Justifications for } \\
\text { the formation of } \\
\text { conflicts of interest }\end{array}$} & Depends on personal background/family upbringing & 19 \\
\hline & Lack of prestige for physicians in partnerships with health care plans & 04 \\
\hline & $\begin{array}{l}\text { Absence of denunciations by co-workers, for the exposure of the one that } \\
\text { denounces }\end{array}$ & 16 \\
\hline & Physicians would only denounce in severe cases & 04 \\
\hline & The CRM (Regional Medical Counsel) only acts in severe cases & 06 \\
\hline & Protectionism by advisors & 02 \\
\hline
\end{tabular}

\section{Analysis and Discussion on Data}

In the focal groups, awkward laughter from the participants were noted by moderators and observers, as they looked at one another with hesitation when the relations between physicians and conflicts of interest was approached, revealing a certain discomfort from physicians, as if they were not willing to discuss the matter.

However, when this first impact moment of the theme was surpassed, which was not brought up spontaneously but provoked by one of the moderators, physicians admitted to know colleagues that received benefits from medical practice, but none of the present themselves admitted to have conflicts of interest of any nature.

Although they affirmed not to have such conflicts, physicians in the focal groups admitted to receive laboratory representatives that took them small prizes and free samples, as if this were a normal pattern without any ethical bias.

\subsection{Physicians and Benefits}

The participants of the focal groups admitted to have knowledge of fellow physicians that received benefits and facilities. The most common practice in the present research, with 21 register units, is the discount or total relief of rent and condominium fees in private practices of physicians who reached a minimum quota of solicited exams in the clinics where they practiced. To reach the desired quota, one may point out the existence of indications, most times unnecessary, of medical procedures in search of further benefits.

Literature makes reference to these same questions and this goes against the ethics code and is the target of media several times, which has the Medical Practice as a preferable object of its publications nowadays. The medical class, on the contrary, must have the responsibility to avoid such events by using the professional ethical code correctly and not allowing the negativity of their image, currently banalized and tarnished [10].

The worst in this practice is that, many times, there is no need for the patient to go through the requested exams. Due to the way certain physicians indicate them, Armstrong [11] and Pimentel [12] suggest that the patient deals with the physician openly, questioning him/her about the importance of the exam.

With specialized physicians, it became easier to have polyvalent services, clinics and even hospitals with multi-professionals as well as diverse services, such as clinical practice, exams performance, therapeutic treatment, etc. This practice leads to the increase on utilization of the medical or hospital environment to realize, in a practical manner for the patient, all necessary procedures in one place. With this, physicians or clinic owners have preference, and consequently larger profit, when compared to physicians who are not interested in this sort of practice [13].

The creation of clinics with specialized physicians leads to the patients' will to consult these professionals for the practicality and agility of the medical consult. This results in patients preferably paying for service instead of waiting for it in the public health system or through the health care plan. As a result, patients have expected de- 
sirable consults and the clinic owners reach their desired profit as well. This system structure to relate physician interest with patient interest is, according to Tonelli [13] ethically acceptable, as long as there is reflection and knowledge of the existence of a conflict of interest in the sense as to diminish its effects and that exams and directions are carried out in an ethical manner.

Physicians, therefore, realize the benefits of opening a condominium with several medical specialties and practices for the realization of exams. The managing medical group receives a condominium fee for expenses with equipment, staff, rent and other items [11] [14].

It is within this vacuum, as stated in the focal groups, that condominium managers, generally physicians as well, request the professionals who work there to order the exams and patient referral to other professionals in the same environment, I order to increase the flow of patients in exchange of reduction or relief of costs, which every physician would have in that condominium in terms of fees and rent.

The matter of conflicts of interest is very complex and requires reflection on what is occurring. It is necessary that physicians prioritize the well-being of the patient, which reflects on greater credibility [10] [15].

In some circumstances, even if there is no conflict of interests, its imminence or the intention to practice it is sufficient to consider its existence positive [13].

Attorneys and specialists in legal structuring of the health care services claim that the practice of referrals within the same environment is being carefully built to avoid illegal situations, once it is difficult to define what is truly non-ethical and what is in benefit to the patient. Before this uncertain scenario, some professionals continue to perform unethically and not use common sense to avoid situations that clearly generate financial benefit [11] [13].

Another issue approached by physicians in the focus groups, with 10 register units, was concerning the benefits offered by the pharmaceutical industry, when fellow physicians prescribe their products. They have affirmed that the greater the number of prescribed medications the more benefits professionals receive, mainly under the form of inscriptions and air plane tickets to congresses and even steady monthly income.

Literature is abundant concerning this theme, pointing out the negative aspects of the relation between physicians and the drug industry. The choice for medication used by the patient must be made by the physician, considering the best pharmacological performance of the medication in each case and considering the cost of obtaining this drug by specific patients. However, what is clear to see are physicians acting according to their own interests and benefits offered by the industry, under the title of royalties, more than often offering benefits to their institutions and research projects in the form of trips to congresses and continued education; some leisure time in huge resorts with the right to an accompanying person or even, in bigger scale, small treats, such as dinners, the most various gifts, from simple ones to the luxurious, etc. [1] [2] [16]-[20].

Physicians must not accept gifts, hospitality, services or subsidies from the industry if there is a price to pay that overshadows their capacity of professional judgment and takes away their autonomy in terms of the choices of what is best for the patient. Authors reveal that, on average, $94 \%$ of physicians have some sort of relation with the pharmaceutical industry [17].

In order to know if the relation is or not ethically proper, Guðmundsson [16] suggests that physicians ask themselves about what would patients think concerning the pact they have with the industry and how would they feel if that were published by the media. The author is not in favor of punishment and believes that peaceful and ethical relations might exist as long as physicians do not succumb to temptation.

Many billions of dollars are invested in marketing by the pharmaceutical industry in the promotion of their products and persuasion of physicians to prescribe their medications. These values are basically spent as gifts and trips (the latter, in smaller scale, are reserved for a privileged few for being highly known of and condemned). But the money is also used in the maintenance of pharmaceutical representatives for contacting professionals, prize and free sample distributions, television and newspaper ads, among others [18] [19] [21] [22].

In the present research, with 6 register units, physicians denied receiving benefits from the industry, but have affirmed, paradoxically, that they received small gifts (pencils, pens, mugs, free samples, note pads, etc.) directly from the pharmaceutical industry representatives that visit them regularly and that this fact does not constitute a conflict of interests. That is, some professionals believe that of the gist is great enough it might influence the physician but smaller gifts do not alter their medical judgment and therefore it is not ethically illicit.

Authors, however, reveal in their research that no matter the size or cost of the gift it will always confuse the physician in his decision ability [5] [20] [23].

Several other authors have the same perception and refer to it in their studies. Among them, Massud [15] who 
concluded that many physicians do not consider themselves influenced by commercial propaganda and justify their belief in this, based in the fact that they also prescribe low cost medications, especially the ones, which have lost the patent, the so-called generic medications.

Another study performed with 1.175 Norwegian physicians revealed the opinion of $39 \%$ of them, who stated that the propaganda from representatives does not influence their personal drug prescriptions and $52 \%$ agree that the physicians work is many times influenced by the industry [24].

The pharmaceutical industry representatives have demonstrated more and more that they are capable of doing anything to increase profit over products from their companies. Many of them do not only offer huge sums of money or benefits but also induce physicians to look for new ways to increase income over the product, by using discount cards on the medication prices. The more money the industry spends with the promotion of their products the fidelity it acquires from physicians [18].

A research published in the American Journal of Bioethics in 2003 [18] points out to the fact that physicians prescribe more medication to which they have access to free samples donated by representatives. Massud [15] confirms this finding by affirming that physicians who receive samples prescribe less and less generic medications and consequently contribute to the increase of expenses with medication.

The physicians in the present study believe they are immune to the influence of the industry when they receive, from the industry representatives, free samples of their products.

There is evidence of reciprocity when someone receives a gift. The industry, which is aware of the marketing theories, knows that.

There is evidence of reciprocity when someone receives a gift. The industry, aware of the theories that support marketing, knows this. Doctors suffer when they receive treats, in effect, the feeling of gratitude and tend to reciprocate the gifts received from the industry. Thus, indirectly, the self-interest and gratitude, consciously or not, can affect the prescriptions, which may not be the ideal for the needs of those who need them [15].

The institutions, including the public ones, create rules, which seem more viable to protect physicians from these influences, but there is no consensus on the decisions that must be established and followed. Even when you create restrictions, the rules always leave a gap for the performance of industry representatives and distribution of free samples [18].

The influence of the pharmaceutical industry in the decisions taken by the doctor may therefore disregard the principles of Bioethics: beneficence, as the best for the patient might not be done, non maleficence if the patient is subjected to adverse reactions that could be avoided, and the principle of justice, because it removes resources, when the medication is distributed by the government, but under the influence of prescription drugs, which could be used by other people more efficiently [15].

The best way to deal with conflicts of interest is preventing its occurrence. Actions can be implemented to ensure an ethical vigilance: the moral education of health professionals, emphasizing the responsibility and intellectual honesty, disclosure of conflicts of interest by learning institutions, research, and scientific journal editors, and control by the committees and councils to evaluate compliance with ethical standards [25].

Among the conflicts of interest the following stand out, in short, representatives' visits to medical laboratories and hospitals; acceptance of gifts and giveaways, participation in social or educational events, continuing medical education, courses or seminars, participation in conferences, participation in research sponsored by industry; purchase shares of pharmaceutical companies, accepting payment of any kind, being a member of the advisory board in the pharmaceutical industry; payment for participation in lectures and conferences, provision of samples, grants for research projects, among others [15].

Ultimately, only the physician is able to stand and act in the most ethical way possible, considering their professionalism and that their medical duty is to care for and suggest the best treatment for the health care of their patients, without the use of certain drugs motivated by receiving bonuses from specific laboratories. Authors recommend reflection about this relationship, which should be maintained in the most ethical and transparent manner as possible [16] [26].

There is nothing that prevents the relationships between physicians and the pharmaceutical industry, or even with drug manipulation pharmacies that also have representatives who make visits to physicians in their offices and offer commissions on sales of their products as revealed in the focus groups of the current study with five register units. The specialties that most manipulate their medications, doctors say, are dermatologists who prescribe and glue the label with the pharmacy address indicated in the actual prescriptions.

Allegations or suspicions will always exist whatever the basis of this relationship, however it is necessary that 
the links established are as transparent as possible. When conflicts are established and justified, as research funding, for example, Duvall [23] suggests making a notification of the types of relationships, financial values and objectives involved, thus making the relationship clearer and less prone to scandals.

Researchers argue in their studies, that the goal of the relationship between physicians and industry is to benefit patients, for these professionals to make the right choice of drug, the literature on the same would be enough to convince them, without the need for pampering to persuade them [21] [27].

As measures of solution it is suggested by Duvall [23], among other things, that any kind gifts from the industry to physicians should be eliminated, including free samples, that all providers of health services with financial ties to industry should be removed, and that transparency of consultation and research increases.

In Brazil, it was a historic moment when the Federal Medical Council/CFM took a leading position, following an international trend, to avoid promiscuous relationships between physicians and industry, through its new Ethics Code, in Resolution no. 1931 on September 17, 2009 and promulgated in March 2010.

It was forbidden, with the new code, that physicians received gifts from the industry, though apparently naive, and also trips, registration at conferences, books, equipment and even consulting rooms assembly, so that the physician were exempted at the time of prescription and not feel compelled however unconsciously, to reciprocate these handouts with his/her prescription, which far from meeting the demands of the patient, had also, however, a commitment to reciprocity with their benefactor [28].

Nevertheless, on February 14, 2012 CFM signed a new agreement between the industry and medical associations, retroacting in the decisions that had been established and celebrated, even internationally, for the positive impact on agencies, boards and associations dedicated to ethics and bioethics worldwide. In the new agreement, trips will be allowed and the industry will be able pay for pampering physicians, as long as they do not have as a criterion how much these physicians prescribe and display their products [28].

Pens, pencil holders and notepads can only be distributed at conferences, paradoxically, however, the previously banned gifts will again be distributed among the physicians in their offices, provided that they do not exceed $\mathrm{R} \$ 200.00$, which is equivalent to $\$ 100.00$ US dollars, and that they are related to clinical practice [28].

It was also established that the industry linked to health should have "objective criteria" to identify physicians who will be invited to meetings, reimbursing registration, transportation, meals and accommodation, excluding leisure and companion costs. CFM, however, has not announced on the occasion of the new agreement, what are these objective criteria. Pimentel [28] states that this is a setback that advances on ethical principles.

\subsection{Agreement between Physicians and the Orthopedic Industry}

Physicians know the existence of harassment and bribery that some experts, among them angiologists, cardiologists, ophthalmologists, plastic surgeons and orthopedic surgeons receive to preferably use their products. With 22 register units, physicians in the focus groups said they had knowledge of the existence of percentages that the prosthetics and orthotics industry, specifically, pays doctors on the value of the cost of materials supplied and used in patients.

Numerous studies indicate that the relationship between physicians and the industry promotes consequences that undermine the autonomy of physicians in the choice of medications, ortheses and prostheses, among other things, for their patients, who ultimately pay for the pampering that the industry provides physicians [29]-[32].

In 2007 the US Justice Department investigated the payment of \$198 million to 932 orthopedic surgeons made by the industry. To avoid criminal prosecution on illegal bribes, companies have accepted an agreement and underwent federal monitoring with new control procedures and transparency, considering it was detected that the manufacturers, under the aegis of consulting, paid percentages on the values of the prostheses used [30].

The companies investigated were: Biomet Orthopedics, DePuy Orthopedics, Inc., Smith \& Nephew plc, Stryker Orthopaedics, and Zimmer, Inc. These companies produce about 95\% of all knee and hip replacements implanted in the United States and it is estimated that in other countries at similar proportion, including Brazil [30].

It was legally established, in the aforementioned agreement, as a way to provide transparency to patients, that the industries would have to provide publicly available information on a website with the names of the beneficiary physicians, their workplace, amounts paid, payment dates and the justification for the receipt. Beneficiary physicians should also inform their patients about these funds coming from the industry [30].

The alleged reasons described in the websites for payments to physicians are varied: consulting, royalties on intellectual property, research funding, meals and trips, among others. Authors consider, in their articles, that the 
term "consulting" is broad and ambiguous [29] [30].

In the analysis of data published in a study proposed by Hockenberry, Weigel, Auerbach and Cram [30], with transparency of information in 2008, the number of surgeons who had financial benefits dropped (526), however, the total amount was nearly $20 \%$ higher compared to the above. The main payment made to a surgeon was $\$ 401,951$ and it was justified, among others, for intellectual property agreements, not necessarily proven.

What the study failed to clarify was the legitimacy of these payments and whether this information was effectively communicated to patients, revealing that the control mechanisms are still precarious, which allows corruption and bribery, leaving the patient on the sidelines of discussions and without a choice [29] [30].

Economic benefits provided by the industry and received by the physicians are understood, finally, as inadequate by the code of ethics of health professionals, the Pharmaceutical Research and Manufacturers of America, the American Medical Association and the American College of Physicians [15].

Steinbrook [29] recognizes an American breakthrough on the way to the requirement of transparency of information provided by the orthopedic industry. He believes corruption is not solved this way but its incidence is inhibited and reduced. He is optimistic about the evolution of the control of all donations and gifts made by the industry related to health, including drugs, made to physicians or educational institutions and research.

\subsection{Justifications for the Illicit}

Survey participants justified the attitude of physicians who commit ethical violations related to conflicts of interest in many respects. There were 19 citations that indicated moral education, character and family and personal values of physicians in the sense of having greater or lesser judgment of what is right, ethical and fair and so allowing themselves or not to be seduced by the industry or clinic owners to prescribe certain medications or indicate diagnostic procedures and facilities in exchange for gifts.

The respondents, with four register units, also tried to justify that these situations occurred due to the current lack of prestige of the category before the health insurance plans that underpay physicians, making them, therefore, vulnerable to the temptations of economic power.

It is possible that some of these conflicts of interest originate in the character and ambition, but also the low wages of some physicians. The issue of income for medical professionals is of paramount importance, even when the decision on the choice of profession and specialty, since it is natural to seek a branch of Medicine that generates more profit for the professional [33] [34].

There is an influence of money in society as a whole. We live in a time when society privileges having at the expense of being, with a departure from the valorization and care for human beings, when they should make investments, for example, in food supplies or health due to millions of underprivileged people. What defines values, in contemporary times, mistakenly, according to Kassirer [32], are the ways in which someone gains and spends their money, conferring you more or less social status.

Physicians must be well paid for their services, but their attitude and ethics must strive for technique, efficiency and elegance, with specific criteria always seeking the welfare of the patient in decision making whenever it is required to request and perform tests and treatments [34].

According to the physicians themselves in their profession, they are the masters of the situation, as layman patients are unable to assess whether their surgery is really necessary or if the medical procedure is adequate. Therefore, they self-regulate their profession and make it an indispensable necessity. The doctor-patient relationship in this case, is nothing but a commercial transaction, where the physician sells his knowledge and health care and the patient is a consumer of these services [34].

According to the philosopher Socrates, there are two kinds of doctors, those who carry out the profession solely motivated by greed of wealth, and those who care about maintaining the life of their patients. Still according to him, the real physicians are those who do not get carried away by greed. That thought does not deny the right of professionals to be rewarded for their work and have money in recognition for their service. But when money becomes the sole motivating factor for the achievement of health service professionals they find themselves facing a serious problem, since the focus of attention to the maintenance of life and its quality is lost and this service is made based on exchanges of interests or incentives that may promote the loss of confidence of the patient or the guardian [34].

The fact that physicians are underpaid in some countries, as pointed out by participants of the present study does not justify corruption, bribery and conflicts of interest. However, the authors acknowledge that this condition is a powerful force behind these events. Thus, without significant increase in medical fees, problems may 
continue. Many doctors, in Poland, for instance, state, according to a study conducted, that some have to choose between working a lot with great responsibility and little pay, or be dishonest and accept bribes [35].

In the focus groups in this research, physicians, with 16 register units, indicated that the ethical issues related to the frequent conflicts of interest involving bribery and corruption, occur due to the lack of denunciations. The Federal Council of Medicine in Brazil does not accept anonymous complaints, so the fellow plaintiffs would have to identify themselves and their exposure might bring undesirable consequences, choosing omission for fear of suffering some type of retaliation. Respondents in focus groups reported (four register units) they have never made done or would do this sort of complaint, unless there was a very serious event involving damage to the patient.

This statement of the research participants suggests a climate of corporatism among physicians, ratified by manifesting their opinions, with six register units, that Regional Medical Councils, in Brazil, would act only in very severe cases.

Physicians in the focus groups also stated that the Regional Councils of Medicine have knowledge about these relations between physicians and the industry, but await formal complaints to take action. With two register units they have also stated that the Councilors demonstrate some type of protectionism when it comes to colleagues who are known offenders. With this positioning, physicians from the present study declare their distrust of the regulatory and supervisory agency of the profession.

Stepke [3] points to the same ideas that were presented in the focus groups, when he states that everyone has multiple interests and motivations, and at some point, it is almost inevitable that these issues are present, including inside ethics counsels and committees. The author continues by saying that the identification of a conflict is not, therefore, a matter of judgment, unless it harms someone's rights or puts them at risk or even promotes damage. In these circumstances, the ethics councils have an important role, but not as the guarantor of justice, neutrality and reliability, considering, he affirms, that it is composed of people who are also fallible and corruptible, also commented by Pisano, Golden and Schweitzer [36].

What has been noticed is that conflicts of interest that physicians face in their relations with the industry is a global problem and affects all nations. Authors are critical to their respective councils and their position on ethical issues, their lack of credibility among professionals and the existing levels of corruption [28] [37].

\section{Conclusions}

The results should be analyzed with a margin of error, since physicians in the focus groups did not wish to even approach this subject, and in a survey like this, its real opinions were not necessarily exposed. Still, it was possible to analyze that the pharmaceutical industry directly influenced the daily practice of physicians, by making them regular visits that were not perceived as an obstacle to autonomy in choosing the best product for each patient.

The conflicts of interest that physicians have not admitted having, but that they were aware of their existence among peers were the following: the seduction that clinic owners make for physicians to generate exams and referrals of patients within the clinic where they have their offices and relieve, as a bonus, their rent and condominium fees; harassment of representatives from pharmaceutical laboratories and manipulated drug pharmacies that offer them in exchange for prescribing, all kinds of benefits, ranging from gifts, to trips and financial values; the bribes that fellow surgeons from certain specialties receive from the industry, especially orthopedic surgeons.

The respondents attempted to justify actions, which were not approved by the code of medical ethics, direct or indirect benefits received from the industry related to health, attributing them to the character and moral values of physicians, acquired within the family, and to the low fees they received in our country.

And lastly, physicians recognize the lack of denunciations related to unlawful acts and, therefore, the lack of punishment encourages links devoid of ethics without reflections on the consequences of conflicts of interest.

Conflicts of interest among medical professionals and the industry related to health, are rich in ethical barriers, mainly because there are no comprehensive and effective laws for its regulation. To combat conflicts of interest, the path is to recognize their existence and its negative interference on medical performance and manage them. The patient care should always be above the existing conflicts so it is possible to minimize risks and maximize benefits for them.

Transparency, besides being a commendable and desirable ethical posture, contributes to a more productive and reliable relation between physicians and their patient. 
Through these reflections, one formulates the wish that physicians, professors and researchers value and convey ethical precepts and teach health care of their patients over the commercial values that mobilize their financial ambition, which fuels conflicts of interest.

\section{Conflict of Interest}

The authors reported no conflict of interest and no funding was received for this work.

\section{References}

[1] Camilleri, M. and Cortese, D.A. (2007) Managing Conflict of Interest in Clinical Practice. Mayo Clinic Proceedings, 82, 607-614. http://dx.doi.org/10.4065/82.5.607

[2] Tattersall, M.H.N. and Kerridge, L.H. (2006) Doctors Behaving Badly? The Medical Journal of Australia, 185, 299300.

[3] Stepke. F.L. (2011) La psiquiatría actual y los conflictos de interés. VII Congreso Virtual de Psiquiatría: Interpsiquis 2006. http://www.psiquiatria.com/articulos/psicosis/25548/?++interactive

[4] Manthous, C.A. (2009) On the Healthcare Question. The American Journal of Bioethics, 9, 1-3. http://dx.doi.org/10.1080/15265160903439438

[5] Kitsis, E.A. (2011) Physicians and the Pharmaceutical Industry: Working Together on Conflict of Interest. The American Journal of Bioethics, 11, 51-52. http://dx.doi.org/10.1080/15265161.2010.535600

[6] Dias, C.A. (2000) Grupo Focal: Técnica de coleta de dados em pesquisas qualitativas. Informação Sociedade, 10, 1-12.

[7] Suanno, M.V.R. (2002) Auto-avaliação institucional: Princípios e metodologia do Grupo focal. In: Bello, J.L.P., Ed., Pedagogia em foco, Rio de Janeiro. http://www.pedagogiaemfoco.pro.br/avinst01.htm

[8] Minayo, M.C. (2006) O desafio do conhecimento. Pesquisa qualitativa em saúde. Hucitec/Abrasco, São Paulo.

[9] Bardin, L. (2004) Análise de Conteúdo. Edições 70, Lisboa.

[10] Steven, Z. and Glickel, M.D. (2009) The Ethics of Espedieny. The Journal of Hand Surgery, 34, 799-807. http://dx.doi.org/10.1016/j.jhsa.2009.03.012

[11] Armstrong, D. (2005) Lucrative Operation: How Some Doctors Turn \$79 Profit from a \$30 Test Physicians Groups Add Markup to Work Done by Others, Despite Ethics Concerns Administrative Costs Cited. The Wall Street Journal, 30, A1-A8.

[12] Pimentel, D. (2012) Consultas curtas, excesso de exames, maior rentabilidade. Revista Somese, 127, 14.

[13] Tonelli, M.R. (2007) Conflict of Interest in Clinical Practice. CHEST, 132, 664-670. http://dx.doi.org/10.1378/chest.07-0315

[14] Bove, A.A. (2009) President's Page: Who Owns What or Whom? Journal of the American College of Cardiology, 54, 1814-1815. http://dx.doi.org/10.1016/j.jacc.2009.10.003

[15] Massud, M. (2010) Conflito de interesses entre os médicos e a indústria farmacêutica. Revista Bioética, 18, 75-91.

[16] Guðmundsson, S. (2005) Doctors and Drug Companies: The Beauty and the Beast? Acta Ophthalmologica Scandinavica, 83, 407-408. http://dx.doi.org/10.1111/j.1600-0420.2005.00524.x

[17] Campbell, E.G., Gruen, R.L., Mountford, J., Miller, L.G., Cleary, P.D. and Blumenthal, D. (2007) A National Survey of Physician-Industry Relationships. The New England Journal of Medicine, 356, 1742-1750. http://dx.doi.org/10.1056/NEJMsa064508

[18] Miller, J.D. (2006) Conflict-of-Interest Spurs New Rules, Not Consensus. Journal of the National Cancer Institute, 98, 1678-1679. http://dx.doi.org/10.1093/jnci/djj508

[19] Marco, C.A., Moskop, J.C., Solomon, R.C., Geiderman, J.M. and Larkin, G.L. (2006) Gifts to Physician from the Pharmaceutical Industry: An Ethical Analysis. Annals of Emergency Medicine, 48, 513-521. http://dx.doi.org/10.1016/j.annemergmed.2005.12.013

[20] Katz, D., Caplan, A.L. and Merz, J.F. (2010) All Gifts Large and Small: Toward an Understanding of the Ethics of Pharmaceutical Industry Gift-Giving. The American Journal of Bioethics, 10, 11-17. http://dx.doi.org/10.1080/15265161.2010.519226

[21] Lambert, L.A., Jenny-Avital, E.R. and Blumenthal, D. (2005) Doctors and Drug Companies. The New England Journal of Medicine, 352, 733-734. http://dx.doi.org/10.1056/NEJM200502173520722

[22] Jost, T.S. (2010) Oversight of Marketing Relationships between Physicians and the Drug and Device Industry: A Comparative Study. American Journal of Law of Medicine, 36, 326-342. 
[23] Duvall, D.G. (2006) Conflict of Interest or Ideological Divide: The Need for Ongoing Collaboration between Physicians and Industry. Current Medical Research and Opinion, 22, 1807-1812. http://dx.doi.org/10.1185/030079906X120977

[24] Aasland, O.G. and Forde, R. (2004) Legers holdninger og praksis i forhold til legemiddelindustrien. Tidsskrift Nor Laegeforen, 124, 2603-2606.

[25] Rotondo, M.T. (2006) Relaciones profesionales: Conflictos de intereses. Revista Médica del Uruguay, 22, 88-99.

[26] Grande, D. (2009) Limiting the Influence of Pharmaceutical Industry Gifts on Physicians: Self-Regulation or Government Intervention? Journal of General Internal Medicine, 25, 79-83. http://dx.doi.org/10.1007/s11606-009-1016-7

[27] Alpert, J.S. (2005) Doctors and the Drug Industry: How Can We Handle Potential Conflicts of Interest? The American Journal of Medicine, 118, 99-100. http://dx.doi.org/10.1016/j.amjmed.2004.12.003

[28] Pimentel, D. (2012) Conselho Federal de Medicina se rende à indústria. Revista Somese, 126, 32.

[29] Steinbrook, R. (2011) Industry Payments to Physicians: Comment on "Financial Payment by Orthopedic Device Makers to Orthopedic Surgeons”. Archives Internal Medicine, 171, 1765-1766. http://dx.doi.org/10.1001/archinternmed.2011.439

[30] Hockenberry, J.M., Weigel, P., Auerbach, A. and Cram, P. (2011) Financial Payments by Orthopedic Device Makers to Orthopedic Surgeons. Archives of Internal Medicine, 171, 1759-1765. http://dx.doi.org/10.1001/archinternmed.2011.454

[31] Taylor, M. (2006) Are Hospitals Next in Line? Government Investigators Probing Relationships between Physicians, Device Makers May Soon Train Sights on Hospitals. Modern Healthcare, 36, 24-26.

[32] White, A.P., Vaccaro, A.R. and Zdeblick, T. (2007) Counterpoint: Physician-Industry Relationships Can Be Ethically Established, and Conflicts of Interest Can Be Ethically Managed. Spine, 32, S53-S57. http://dx.doi.org/10.1097/BRS.0b013e318053d54f

[33] Kassirer, J.P. (2007) Commercialism and Medicine: An Overview. Cambridge Quarterly of Healthcare Ethics, 16, 377-386. http://dx.doi.org/10.1017/S0963180107070478

[34] Gunderman, R.B. and Hubbard, M.A. (2005) The Wages of Healing: Ethical Issues in the Compensation of Physicians. Medical Science Monitor, 11, 5-10.

[35] Czupryniak, L. and Loba, J. (2004) Route of Corruption in Poland’s Health-Care System. The Lancet, 364, 1856. http://dx.doi.org/10.1016/S0140-6736(04)17436-9

[36] Pisano, E., Golden, N. and Schweitzer, L. (2014) Conflict of Interest Policies for Academic Health System Leaders Who Work with Outside Corporations. JAMA, 311, 1111-1112. http://dx.doi.org/10.1001/jama.2014.788

[37] Nagral, J. and Roy, N. (2010) The Medical Council of India Guidelines on Industry-Physician Relationship: Breaking the Conspiracy of Silence. The National Medical Journal of India, 23, 69-71. 
Scientific Research Publishing (SCIRP) is one of the largest Open Access journal publishers. It is currently publishing more than 200 open access, online, peer-reviewed journals covering a wide range of academic disciplines. SCIRP serves the worldwide academic communities and contributes to the progress and application of science with its publication.

Other selected journals from SCIRP are listed as below. Submit your manuscript to us via either submit@scirp.org or Online Submission Portal.
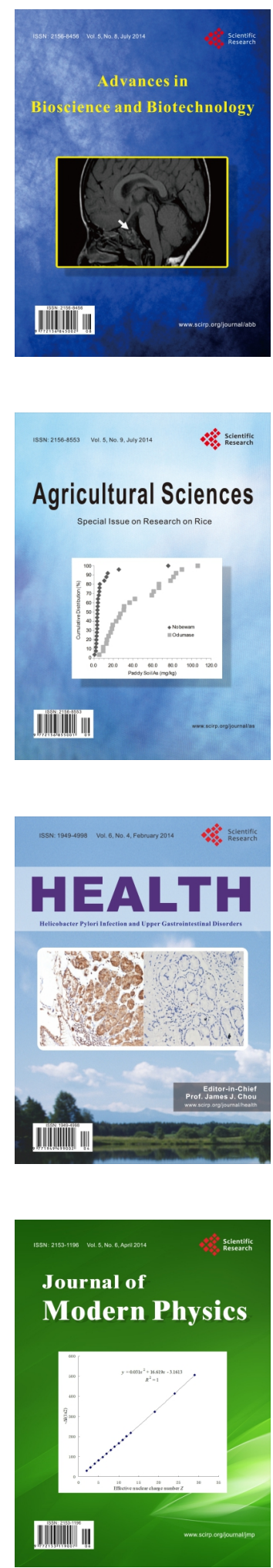
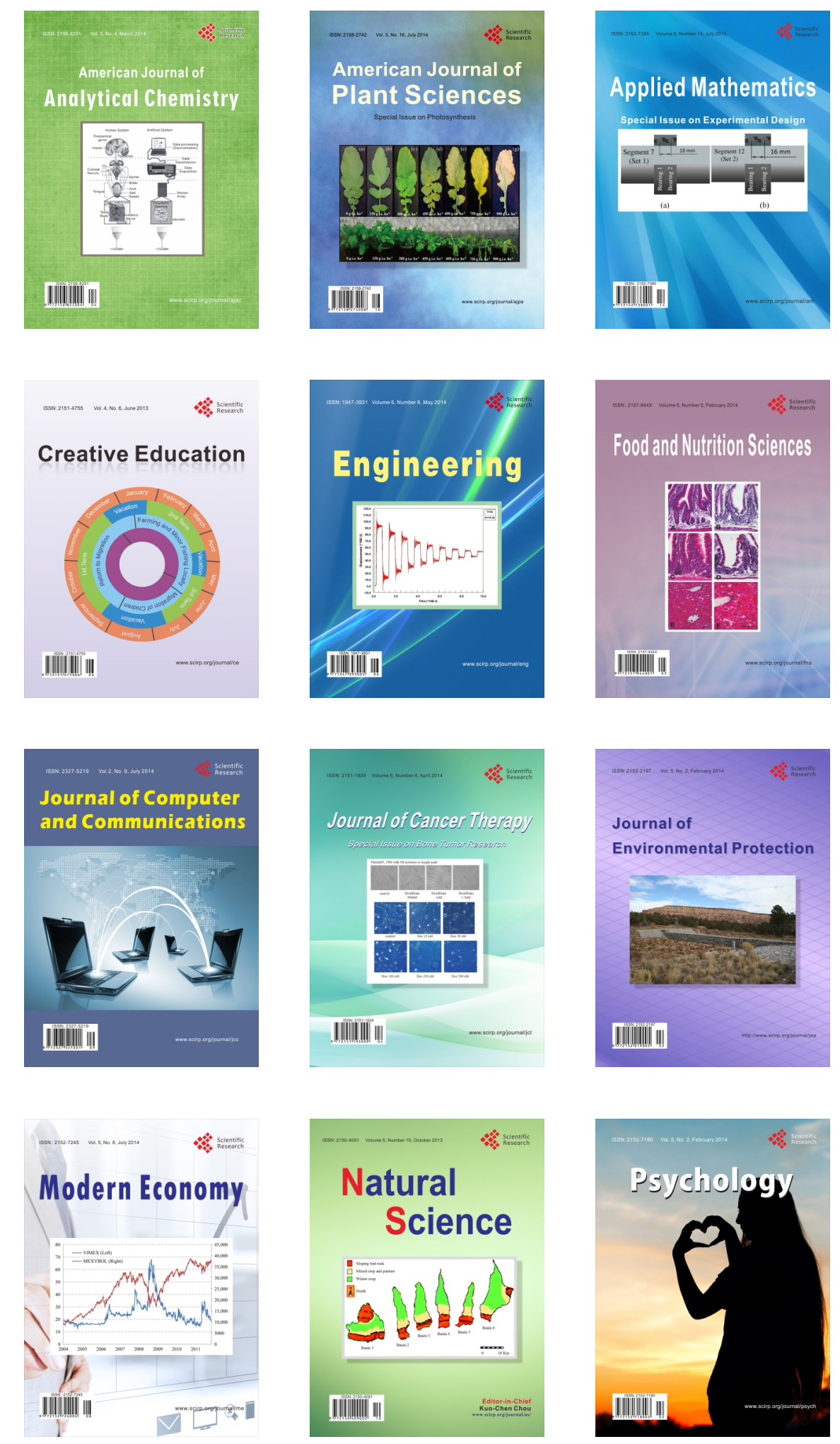